\title{
Alveolar Recruitment Promotes Homogeneous Surfactant Distribution in a Piglet Model of Lung Injury
}

\author{
MARTIN F. KRAUSE, CORNELIA JÄKEL, JÖRG HABERSTROH, JÜRGEN SCHULTE-MÖNTING \\ JEKABS U. LEITITIS, AND MARZENNA ORLOWSKA-VOLK \\ Departments of Pediatrics [M.F.K., C.J., J.U.L.], Surgery [J.H.], Medical Biometry and Statistics \\ [J.S.-M.], and Pathology [M.O.-V.], Albert-Ludwigs-University, Medical School, 79106 \\ Freiburg, Germany
}

\begin{abstract}
Uneven distribution of exogenous surfactant contributes to a poor clinical response in animal models of respiratory distress syndrome. Alveolar recruitment at the time of surfactant administration may lead to more homogeneous distribution within the lungs and result in a superior clinical response. To investigate the effects of three different volume recruitment maneuvers on gas exchange, lung function, and homogeneity of surfactant distribution, we studied 35 newborn piglets made surfactant deficient by repeated airway lavage with warm saline. Volume recruitment was achieved by either a temporal increase in tidal volume or an increase in end-expiratory pressure during surfactant administration, yielding an increase in dynamic compliance of the respiratory system of $77 \%$ in the first group and an increase in functional residual capacity of $108 \%$ in the second group. A third group of piglets (all $n=7$ ) received a combination of both volume recruitment maneuvers, with increases in dynamic compliance of the respiratory system of $100 \%$ and in functional residual capacity of $192 \%$. Those animals subjected to increased tidal volume showed an improved surfactant response in terms of oxygenation, ventilation, lung volumes, lung mechanics, and homogeneity of surfactant distribution. Increased end-expiratory volume augmented the surfactant effect only to some extent. The combination of both volume recruitment maneuvers, however,
\end{abstract}

\section{ABSTRACT}

needed lung volumes beyond total lung capacity (approximately $56 \mathrm{~mL} / \mathrm{kg}$ ), thus probably inducing early sequelae of ventilatorinduced lung injury. We conclude that volume recruitment by means of increased tidal volumes at the time of surfactant administration leads to a superior surfactant effect owing to more homogeneous surfactant distribution within a collapsed lung. (Pediatr Res 50: 34-43, 2001)

\section{Abbreviations}

CRS, dynamic compliance of the respiratory system

ETT, endotracheal tube

$\mathrm{Fio}_{2}$, fraction of inspired oxygen

FRC, functional residual capacity

$\mathrm{PaCO}_{2}$, arterial $\mathrm{PCO}_{2}$

$\mathrm{PaO}_{2}$, arterial $\mathrm{Po}_{2}$

$\mathbf{P A O}_{2}$, alveolar $\mathrm{PO}_{2}$

PEEP, positive end-expiratory pressure

RDS, respiratory distress syndrome

TLC, total lung capacity

$\mathbf{V}_{\text {A, alveolar volume }}$

$\mathbf{V}_{\mathrm{T}}$, tidal volume

VILI, ventilator-induced lung injury

VRM, volume recruitment maneuver
Surfactant treatment has reduced mortality and morbidity in infants with RDS (1). However, detrimental factors affecting response to therapy are numerous, such as uneven distribution of exogenous surfactant, insufficient dosage, inability of exogenous surfactant to enter the metabolic pathways, inhibition of surface activity by plasma-derived proteins, or respiratory failure caused by factors other than surfactant deficiency (2).

Received May 4, 2000; accepted October 10, 2000

Correspondence and reprint requests: Martin F. Krause, M.D., University Children's Hospital, Schwanenweg 20, D-24105 Kiel, Germany; e-mail: m.krause@ pediatrics.uni-kiel.de

Supported by Grant KR 1863/1-1 from Deutsche Forschungsgemeinschaft (Dr. Krause).
Two clinical studies $(3,4)$ have identified patent ductus arteriosus, gas accumulation outside the alveolar level, and pulmonary infection as the main reasons for nonresponse in neonates with RDS, leading to an increased mortality as high as $40 \%$ of affected infants. Poor response, however, is thought to be predominantly caused by uneven surfactant distribution. Animal studies have shown that the distribution of exogenous surfactant is often nonuniform, and that nonuniform distribution patterns are associated with poor clinical response (5-7).

The immediate increase in FRC after surfactant administration to infants with RDS $(8-10)$ can be considered to be the result of two mechanisms: stabilization of previously collapsing alveoli at end-expiration, and stabilization of alveoli already being ventilated at higher end-expiratory volumes. When 
end-inspiratory and end-expiratory airway pressures are held constant during mechanical ventilation, stabilization without recruitment results in a decrease in lung compliance measured between the two pressures whereas recruitment of previously unventilated alveoli increases compliance (11). The lack of improvement in compliance immediately after surfactant treatment in infants with RDS $(8-10,12,13)$ at a time when gas exchange and lung volume have already improved suggests the possibility that a substantial compartment of unventilated alveoli still exists. If so, mechanical recruitment of unventilated alveoli accompanying surfactant administration might lead to a superior clinical response of exogenous surfactant in terms of gas exchange and lung function owing to a more homogeneous pattern of distribution.

To test this hypothesis, three different VRMs were evaluated in newborn piglets made surfactant deficient by repeated airway lavage. The first maneuver used increased tidal volumes in an attempt to recruit previously unventilated alveoli, the second used increased PEEP to achieve higher end-expiratory volumes, and the third consisted of a combination of both maneuvers. We expected an improved lung compliance by the first maneuver and an increased FRC by the second maneuver promoting a more homogeneous surfactant distribution when compared with surfactant administration without alveolar recruitment. In a second step we tried to match improved gas exchange and lung function with a more homogeneous pattern of surfactant distribution at the alveolar level by the use of a new staining technique for exogenous surfactant.

\section{MATERIALS AND METHODS}

Animal preparation. The experimental protocol was approved by the local Review Board for the Care of Animal Subjects in accordance with the German law for animal protection and the European Community guidelines (86/609/EC).

Thirty-five piglets (mixed country breed) of either sex from five litters were studied between day 2 and 14 of age, weighing $2.4 \pm 0.4 \mathrm{~kg}$ (range, $1.7-4.3 \mathrm{~kg}$ ). Initially $0.05 \mathrm{mg} / \mathrm{kg}$ atropine, $10 \mathrm{mg} / \mathrm{kg}$ ketamine, and $1 \mathrm{mg} / \mathrm{kg}$ midazolam hydrochloride were administered intramuscularly to provide anesthesia. Oral intubation with an uncuffed 3.0-mm inner diameter ETT was performed after the administration of $2 \mathrm{mg} / \mathrm{kg}$ propofol i.v. via a catheter in an ear vein. Anesthesia and muscle paralysis were maintained by continuous i.v. infusion of $15 \mathrm{mg} / \mathrm{kg}$ propofol and $0.2 \mathrm{mg} / \mathrm{kg}$ pancuronium bromide per hour throughout the study period. To prevent leakage the ETT was tightly secured in place by a peritracheal ligature. A polyvinyl catheter was inserted into the left common carotid artery for monitoring of arterial blood pressure and arterial blood gases. The right ventricle was catheterized via a catheter inserted into the right external jugular vein to obtain mixed venous blood samples and monitoring of right ventricular blood pressure.

Mechanical ventilation and airway lavage. Mechanical ventilation was provided by two time-cycled pressure-limited infant ventilators (Babylog 1, Dräger, Germany). The following ventilator settings were used: $\mathrm{Fio}_{2}, 0.6$; PEEP, $0.4 \mathrm{kPa}$; flow, $8 \mathrm{~L} / \mathrm{min}$; inspiratory time, $0.4 \mathrm{~s}$; and ventilator rate, 35 breaths/min before lavage and 60 breaths/min during and immediately after lavage. PIP was adjusted to keep tidal volume (VT) at $8 \mathrm{~mL} / \mathrm{kg}$.

We used a modification of the original lavage protocol described by Lachmann et al. (14). Each lavage involved the instillation and removal of $35 \mathrm{~mL} / \mathrm{kg}$ of warmed normal saline via the ETT carried out over a 30 -s period. After the first lavage, PEEP was increased to $0.8 \mathrm{kPa}$ and the ventilator rate to 60 breaths/min to ensure adequate oxygenation and ventilation and to hasten surfactant removal and alveolar collapse (15). The first six lavages were performed in changing side positions. Airway lavage was repeated every 3-6 min until both the $\mathrm{PaO}_{2}$ decreased to $5.3-6.6 \mathrm{kPa}$, and a minimum PIP of $>1.8 \mathrm{kPa}$ was required to maintain $\mathrm{V}_{\text {т }}$ at $8 \mathrm{~mL} / \mathrm{kg}$. Twenty minutes later two more lavages were performed to remove surfactant released into the alveoli by the sympathetic stimulus from the lavage procedure $(16,17)$. Before baseline measurements the original PEEP level of $0.4 \mathrm{kPa}$ was reestablished following a modified protocol by Dijk et al. (18).

Loss of lavage fluid within the airways was noted for comparability of study animals among groups. In addition, the lavage fluid was centrifuged at $2500 \mathrm{rpm}$ for $10 \mathrm{~min}$ to determine the amount of alveolar wash when separated from saline and cellular debris.

Experimental protocol. Measurements of gas exchange $\left(\mathrm{PaO}_{2}\right.$ and $\left.\mathrm{PaCO}_{2}\right)$, lung function indices (FRC, $\mathrm{V}_{\mathrm{A}}, \mathrm{VT}$, and $\left.\mathrm{CRS}_{\mathrm{RS}}\right)$ and hemodynamic variables (heart rate, systemic and right ventricular blood pressures, and venous admixture) were made before airway lavage and after airway lavage at baseline and at $5,30,60,90$, and $120 \mathrm{~min}$ after intervention (i.e. surfactant administration with or without a VRM). Ventilator rate was maintained at 60 breaths/min until completion of the surfactant administration protocol and was then switched back to 35 breaths/min throughout the remainder of the study. In contrast, animals of the control group continued being ventilated at 60 breaths $/ \mathrm{min}$.

At baseline the animals were randomized to one of the following protocols (all $n=7$ ): a control group (Control) receiving $5.5 \mathrm{~mL} / \mathrm{kg}$ of air into a second lumen of the ETT; a group (Surf) receiving $5.5 \mathrm{~mL} / \mathrm{kg}$ surfactant only (this group was serving as the true control group for statistical analysis); a group (VT16) receiving $5.5 \mathrm{~mL} / \mathrm{kg}$ surfactant concomitantly with an increased $\mathrm{V}_{\mathrm{T}}$ of $16 \mathrm{~mL} / \mathrm{kg}$ (intervention group 1); a group (P8) receiving $5.5 \mathrm{~mL} / \mathrm{kg}$ surfactant concomitantly with an increased PEEP of $0.8 \mathrm{kPa}$ (intervention group 2); and a group $\left(\mathrm{V}_{\mathrm{T}} 16+\mathrm{P} 8\right)$ receiving $5.5 \mathrm{~mL} / \mathrm{kg}$ surfactant concomitantly with an increased $\mathrm{V}_{\mathrm{T}}$ of $16 \mathrm{~mL} / \mathrm{kg}$ and an increased PEEP of $0.8 \mathrm{kPa}$ (intervention group 3).

The VRMs were applied for 5 min before surfactant administration, during surfactant administration $(2 \mathrm{~min})$, and for another $5 \mathrm{~min}$ after surfactant administration. After this period of $12 \mathrm{~min}$, the ventilator rate was switched back to 35 breaths/ min as was done in the Surf group immediately after surfactant administration. Vт was then allowed to vary along with increases or decreases in CRS after surfactant administration.

Surfactant preparation and administration. The surfactant preparation used in this study was Curosurf (Serono, Unterschleißheim, Germany), an organic solvent of pig lung purified by chromatography containing phospholipids $\mathrm{B}$ and $\mathrm{C}$, at a 
concentration of $40 \mathrm{mg} / \mathrm{mL}$ after dilution with equal amounts of normal saline to promote its physiologic response (6). A diluted green histology dye (Green Tissue Marking Dye, WAK-Chemie Medical, Bad Soden, Germany) was mixed with the surfactant preparation, adding an additional 1/10 volume to the surfactant preparation, and hand-stirred for $5 \mathrm{~min}$. The original dye preparation was diluted 1:10 with normal saline before adding to surfactant as previously described (19). All animals of the intervention groups received $200 \mathrm{mg} / \mathrm{kg}$ Curosurf equivalent to a volume of $5.5 \mathrm{~mL} / \mathrm{kg}$ via a second lumen of the ETT within $2 \mathrm{~min}$ (20) regardless of the absolute amount of fluid administered and without interrupting mechanical ventilation.

Measurement of gas exchange, hemodynamics, and lung function indices. $\mathrm{PaO}_{2}$ and $\mathrm{PaCO}_{2}$ were measured from blood samples taken from the carotid arterial catheter.

Intrapulmonary right-to-left shunt (venous admixture) was calculated by Fick equation $\left[\left(\mathrm{CaO}_{2}-\mathrm{CcO}_{2}\right) /\left(\mathrm{CVO}_{2}-\mathrm{CcO}_{2}\right)\right]$. $\mathrm{PaO}_{2}$ and $\mathrm{PCO}_{2}$ were measured from arterial and mixed venous blood samples taken from the carotid arterial catheter and the right ventricular catheter, respectively, and used to calculate arterial $\left(\mathrm{CaO}_{2}\right)$ and mixed venous $\left(\mathrm{CVO}_{2}\right)$ oxygen contents. Alveolar capillary $\mathrm{O}_{2}$ content $\left(\mathrm{CCO}_{2}\right)$ was calculated by using $\mathrm{PAO}_{2}$ from the alveolar gas equation with $\mathrm{PAO}_{2}=\left[\left(\mathrm{PB}_{\mathrm{B}}-6.25\right)\right.$ $\times \mathrm{FiO}_{2}-\mathrm{PaCO}_{2}$ ], where $\mathrm{PB}$ is barometric pressure. Blood gases were analyzed using an ABL 500 (Radiometer, Copenhagen, Denmark), and oxygen saturation was measured with a hemoximeter (OSM3, Radiometer, Copenhagen, Denmark), which adjusts oxygen saturation to the specific $\mathrm{Hb}$ of pigs.

To calculate FRC, $\mathrm{V}_{\mathrm{A}}, \mathrm{V}_{\mathrm{T}}$, and $\mathrm{C}_{\mathrm{RS}}$, we used the lung function technique described by Sjöqvist et al. $(21,22)$ and Edberg et al. (23). The airflow signal was derived from a differential pressure transducer (Dr. Fenyves und Gut, Hechingen, Germany) and a Fleisch No. 00 pneumotachometer (Fleisch, Lausanne, Switzerland) attached to the ETT connector.

FRC and $\mathrm{V}_{\mathrm{A}}$ were measured using a multiple-breath nitrogen washout technique (22) with a model 721 Nitralyzer (KaeTech Instruments, Green Bay, WI, U.S.A.) to measure nitrogen concentration in respiratory gas mixtures. CRS was estimated by the least squares method by fitting airflow and $\mathrm{V}_{\mathrm{T}}$ signals to proximal airway pressure using the standard equation of motion (21-23).

Airflow, pressure, and nitrogen signals used for measuring lung function indices were sampled at a rate of $200 \mathrm{~Hz}$, digitized, and stored in a personal computer for subsequent analysis. Data acquisition and analysis was done using a lung function analysis software by Ants R. Silberberg from Chalmers University of Technology, Gothenburg, Sweden, also using the software program Matlab 5.3 (The MathWorks Inc., Natick, MA, U.S.A.) for data analysis.
Clinical care. A heating pad was used to maintain a constant core temperature of the piglets between $38^{\circ}$ and $39^{\circ} \mathrm{C}$, as measured by a rectal probe. Each piglet received an infusion of $10 \%$ dextrose in water at $5.5 \mathrm{mg} \cdot \mathrm{kg}^{-1} \cdot \mathrm{min}^{-1}$ glucose and a fluid intake of $80 \mathrm{~mL} \cdot \mathrm{kg}^{-1} \cdot \mathrm{d}^{-1}$. The pressure transducers were flushed with normal saline containing $2 \mathrm{IU}$ heparin $/ \mathrm{mL}$.

Volume-pressure curves. At the end of the clinical study period, at 120 min after surfactant administration, the lungs of the animals were degassed by applying an $\mathrm{Fio}_{2}$ of 1.0 for $3 \mathrm{~min}$ before clamping the ETT and discontinuing mechanical ventilation; the animals were in deep narcosis with propofol. After $3 \mathrm{~min}$, the animals were killed with an overdose of $1 \mathrm{M} \mathrm{KCl}$. Quasi-static volume-pressure curves were obtained by manual inflation with calibrated syringes in pressure steps of $0.66 \mathrm{kPa}$ up to a maximum of $3.3 \mathrm{kPa}$ and by withdrawing volume in discrete steps of $0.66 \mathrm{kPa}$ back to atmospheric airway pressure as described by Venegas et al. (24). Comparisons of the three groups were made at opening pressure of $1.33 \mathrm{kPa}$ as the lungs were inflated, at maximal lung volume $(3.3 \mathrm{kPa})$, and at a point that reflects deflation stability at $0.66 \mathrm{kPa}$ as lungs were deflated, according to Jobe (25).

Histologic processing. After tying off the trachea to prevent efflux of stained surfactant from the airways into the fixation fluid, the lungs were removed from the thorax and put into $4 \%$ formaldehyde for several days. Ten cuts of lung at a width of $3 \mu \mathrm{m}$ were taken from central and peripheral locations of each lobe and mounted on slides for fixation. All slides were stained with hematoxylin and eosin using standard methods. A score was established [0-5 points for each index (we also used steps of 0.5 points): 0 , not at all; 1 , very little; 2 , little; 3 , moderate; 4, moderate to severe; 5, severe] describing emphysema and atelectasis; edema; infiltration with polymorphonuclear leukocytes and lymphocytes; invasion with macrophages, giant macrophages, and erythroblasts; bleeding; and hyaline membranes. Distribution of the stained surfactant within the lung was assessed by another score ( $0-5$ points: from 0 indicating very inhomogeneous to 5 indicating very homogeneous) differentiating between right upper lobe, right middle lobe, right lower lobe, left upper lobe, and left lower lobe. Photographs were taken to demonstrate morphologic changes and the pattern of surfactant distribution at the alveolar level.

Statistical methods. To establish comparability of the five experimental groups before surfactant administration, we used a Kruskal-Wallis test to assess differences in the number of lavages, loss of lavage fluid, and alveolar wash (Table 1). The indices of gas exchange $\left(\mathrm{PaO}_{2}, \mathrm{PaCO}_{2}\right)$, venous admixture, and the four indices of lung function (FRC, $\mathrm{V}_{\mathrm{A}}, \mathrm{V}_{\mathrm{T}}$, and $\mathrm{CRS}_{\mathrm{RS}}$ ) after lavage (at baseline) were compared using a one-way ANOVA. Efficacy of volume recruitment (Table 2) was assessed using a paired $t$ test. Repeated measures ANOVA with StudentNeuman-Keuls post hoc testing was used to assess differences

Table 1. Comparability of experimental groups: number of lavages, loss of lavage fluid, and amount of alveolar wash

\begin{tabular}{lccrrrr}
\hline \multicolumn{1}{c}{ Variable } & Control & Surf & Vт16 & P8 & Vт16 + P8 & $p$ \\
\hline Number of lavages & $10.4 \pm 2.7$ & $18.4 \pm 6.3$ & $15.4 \pm 5.1$ & $17.0 \pm 9.3$ & $15.7 \pm 4.6$ & 0.12 \\
Loss of lavage fluid (\%) & $10.1 \pm 2.0$ & $6.8 \pm 2.6$ & $7.5 \pm 2.5$ & $8.2 \pm 3.8$ & $6.5 \pm 1.7$ & 0.11 \\
Alveolar wash (mg) & $373 \pm 205$ & $912 \pm 517$ & $841 \pm 317$ & $712 \pm 380$ & $822 \pm 311$ & 0.07 \\
\hline
\end{tabular}

$n=7$ for all groups. 
Table 2. Impact of VRM (by increased PEEP or PIP) on FRC, $V_{A}$ and $C_{R S}$

\begin{tabular}{|c|c|c|c|}
\hline Variable & Vт16 & P8 & Vт16 + P8 \\
\hline PEEP (kPa) & 0.4 & 0.8 & 0.8 \\
\hline \multicolumn{4}{|l|}{ PIP (kPa) } \\
\hline At baseline & $2.20 \pm 0.15$ & $2.15 \pm 0.19$ & $2.25 \pm 0.23$ \\
\hline Volume recruitment & $2.94 \pm 0.34 * * *$ & $2.38 \pm 0.13 * *$ & $3.37 \pm 0.22 * * *$ \\
\hline Delta & $0.74 \pm 0.25$ & $0.22 \pm 0.12$ & $1.11 \pm 0.25$ \\
\hline \multicolumn{4}{|l|}{ FRC $(\mathrm{mL} / \mathrm{kg})$} \\
\hline At baseline $\dagger$ & $13.2 \pm 3.4$ & $13.4 \pm 4.2$ & $13.7 \pm 3.4$ \\
\hline Volume recruitment & $23.9 \pm 7.8^{* * *}$ & $28.0 \pm 10.4^{* * *}$ & $40.1 \pm 8.4 * * * *$ \\
\hline Delta & $10.6 \pm 5.6$ & $14.5 \pm 6.5$ & $26.4 \pm 6.9$ \\
\hline \multicolumn{4}{|l|}{$\mathrm{V}_{\mathrm{A}}(\mathrm{mL} / \mathrm{kg})$} \\
\hline At baseline $\dagger$ & $1.7 \pm 0.4$ & $1.6 \pm 0.7$ & $1.8 \pm 0.5$ \\
\hline Volume recruitment & $4.2 \pm 1.5^{* *}$ & $1.7 \pm 0.3$ & $5.9 \pm 1.4 * * * *$ \\
\hline Delta & $2.5 \pm 1.5$ & $0.1 \pm 0.4$ & $4.2 \pm 1.3$ \\
\hline \multicolumn{4}{|c|}{$\mathrm{CRS}\left(\mathrm{mL} \cdot \mathrm{kPa}^{-1} \cdot \mathrm{kg}^{-1}\right)$} \\
\hline At baseline $\dagger$ & $8.0 \pm 1.3$ & $7.1 \pm 1.3$ & $6.8 \pm 0.8$ \\
\hline Volume recruitment & $14.2 \pm 1.6^{* * * *}$ & $9.0 \pm 1.5^{* * *}$ & $13.6 \pm 1.5^{* * * *}$ \\
\hline Delta & $6.2 \pm 1.7$ & $1.8 \pm 0.6$ & $6.7 \pm 1.4$ \\
\hline
\end{tabular}

$* * p<0.01 ; * * * p<0.001 ; * * * *<0.0001$ (paired $t$ test).

$\dagger$ There were no significantly different results for FRC, VA, and CRS at baseline among groups.

among groups in change over time for the seven indices (Figs. 1 and 2). For missing values a one-way ANOVA was also used to assess differences in pressure-volume curves (Fig. 3) among groups at $1.33 \mathrm{kPa}$ (opening pressure), $3.3 \mathrm{kPa}$ (maximal lung volume), and $0.66 \mathrm{kPa}$ (deflation stability). A Friedman test was used to evaluate differences in histology score and surfactant distribution (Figs. 4 and 5), followed by Dunn's multiple comparison test in case of significant differences. Comparison of surfactant distribution among groups summarizing the scores of all five lung lobes (Fig. 5, "All lobes") were assessed using a Wilcoxon rank sum test.

Mean values \pm SD are expressed unless specified otherwise. Histology scores are displayed as box and whisker plots. Significant differences among groups were assumed to be present at values of $p<0.05$.

\section{RESULTS}

Comparability of study groups. Thirty-five piglets from five litters at an age of $5.9 \pm 3.3 \mathrm{~d}$ (range, $2-14 \mathrm{~d}$ ) and weighing 2.4 $\pm 0.4 \mathrm{~kg}$ (range, $1.7-4.3 \mathrm{~kg}$ ) were consecutively studied after randomization at the completion of airway lavage. [Five more piglets were studied that died before randomization because of hypoxia and acidosis $(n=2)$, right atrial catheter perforation $(n=2)$, and congenital heart disease with severe pulmonary hypertension $(n=1)$ ]. Table 1 displays some differences, although statistically insignificant, in the number of lavages used and the amount of alveolar wash gathered from airway lavage. The control group animals (stemming from two litters only in accord with the randomization protocol; differences among litters probably because of study animals not from inbred species) needed fewer lavages to achieve a $\mathrm{PaO}_{2}$ between 5.3 and $6.6 \mathrm{kPa}$, also yielding less alveolar wash than piglets of the other groups.
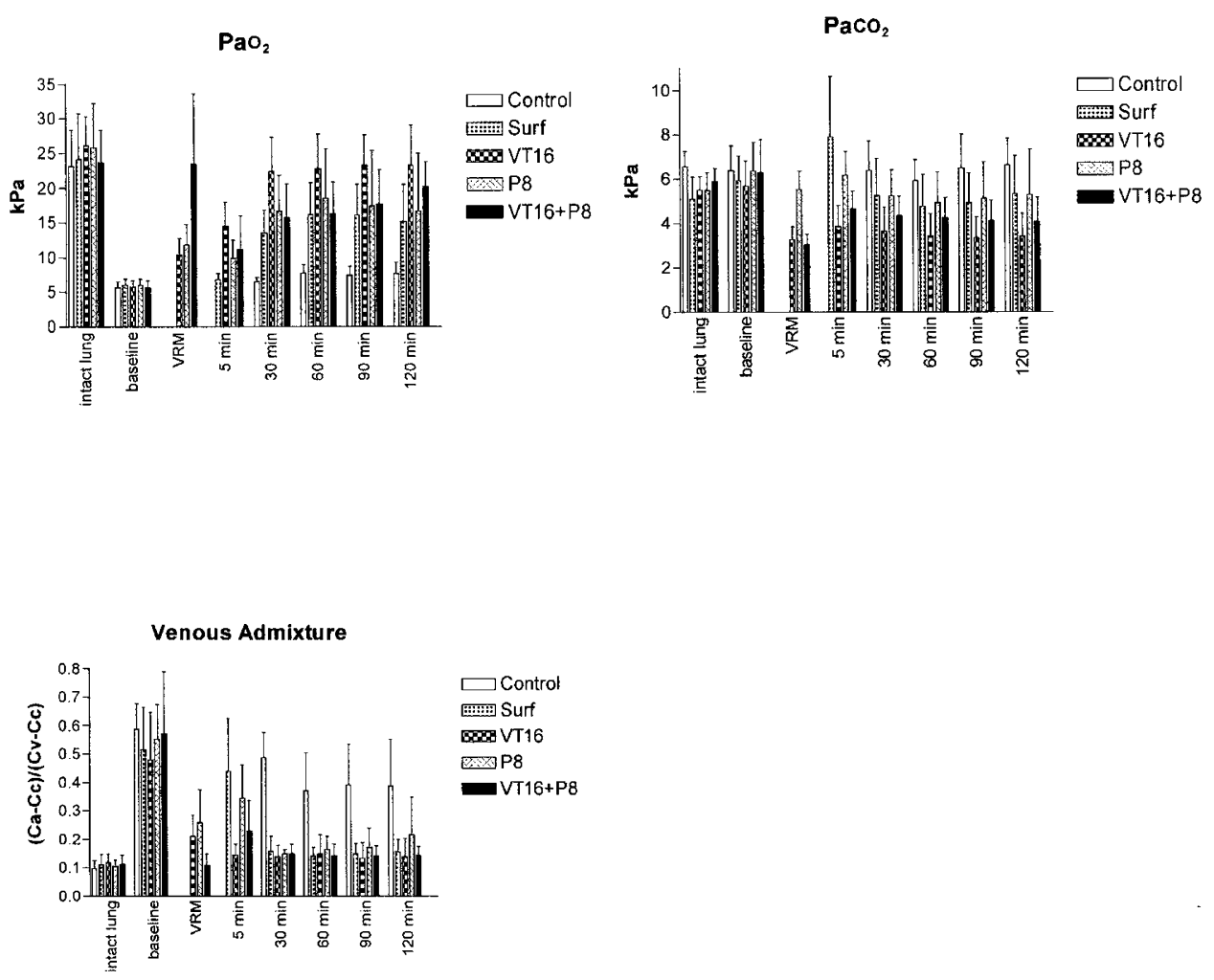

Figure 1. $\mathrm{PaO}_{2}, \mathrm{PaCO}_{2}$, and venous admixture before and after lavage, during a VRM, and over time for a study period of 120 minutes. Control group not included for statistical assessment (repeated measures ANOVA). $\mathrm{PaO}_{2}$ and $\mathrm{PaCO}_{2}$ showed highly significant differences among groups (both $p<0.0001$ ); venous admixture was not different $(p=0.18)$. Student-Newman-Keuls post hoc testing revealed significant differences among the three groups receiving a VRM in favor of the Vт16 group, yielding superior results when compared with $\mathrm{P} 8$ and $\mathrm{VT} 16+\mathrm{P} 8$ for $\mathrm{PaO}_{2}$ and $\mathrm{PaCO}_{2}$. 

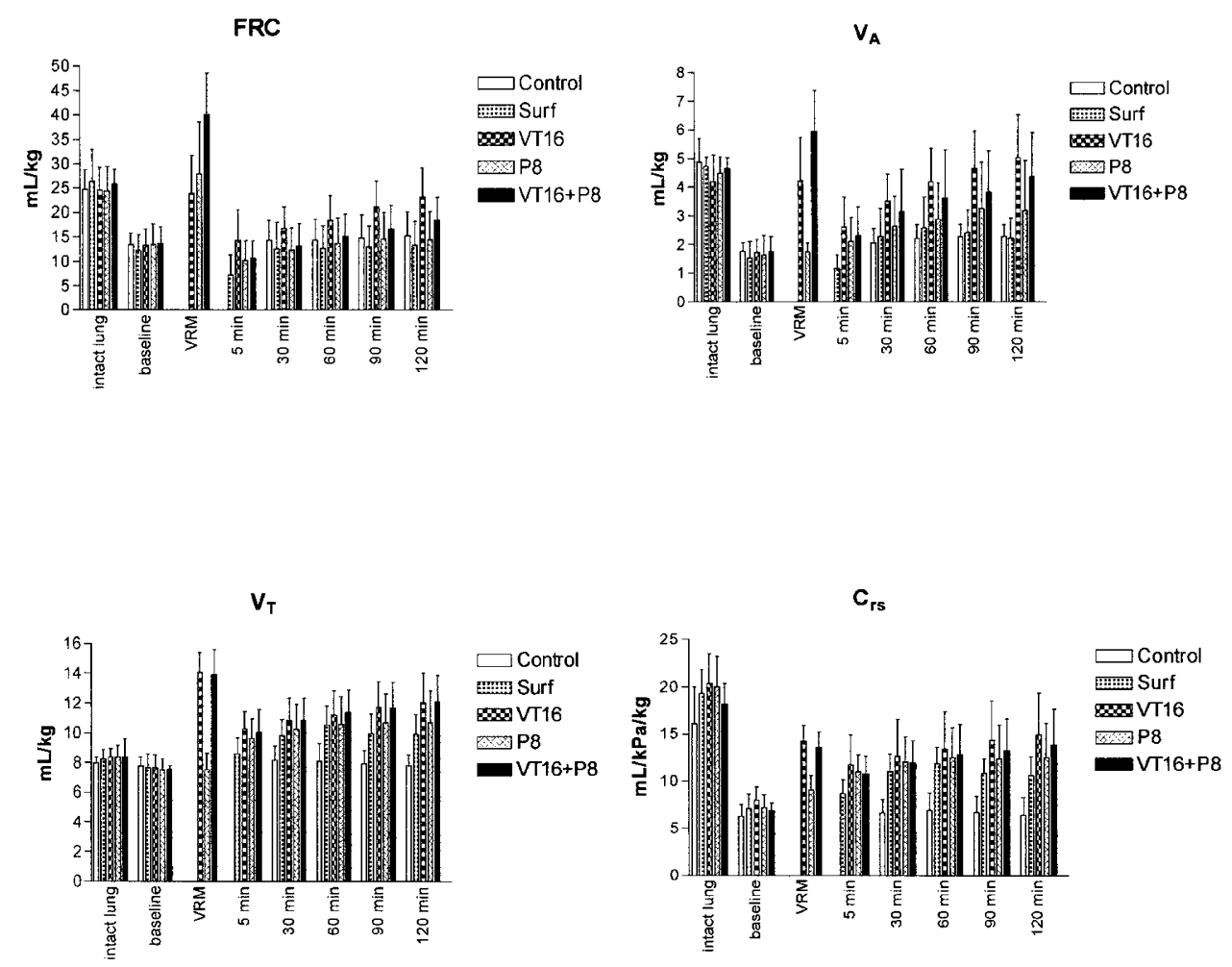

Figure 2. Four indices of lung function (FRC, VA, VT, and CRs) before and after lavage, during a VRM, and over time for a study period of 120 minutes. Control group not included for statistical assessment (repeated measures ANOVA). FRC, VA, VT, and CRS showed highly significant differences among groups (all $p<$ 0.0001). Student-Newman-Keuls post hoc testing revealed significant differences among the three groups receiving a VRM in favor of the VT16 group, yielding superior results when compared with P8 and VT16+P8 for FRC, VA, Vt (only Vt16+P8 vs P8), and Crs.

At baseline (completion of airway lavage) there were no statistically significant differences among the five groups for $\mathrm{PaO}_{2}, \mathrm{PaCO}_{2}$, venous admixture, FRC, VA, VT, and CRS.

VRMs. There were no significantly different results for FRC, $\mathrm{V}_{\mathrm{A}}$, and $\mathrm{CRS}_{\mathrm{RS}}$ at baseline for the three intervention groups subjected to VRMs (Table 2). The increase in FRC was most pronounced in the $\mathrm{V}_{\mathrm{T}} 16+\mathrm{P} 8$ group, yielding exactly the sum of both increases from the $\mathrm{V}_{T} 16$ and P8 intervention groups. Significant increases in $\mathrm{V}_{\mathrm{A}}$ were noted in the $\mathrm{V}_{\mathrm{T}} 16$ and $\mathrm{V}_{\mathrm{T}} 16+\mathrm{P} 8$ groups also, demonstrating effective alveolar recruitment by the increase in $\mathrm{V}$.

Change in gas exchange, hemodynamics, and lung function indices over time. Figures 1 and 2 display seven variables of gas exchange, hemodynamics, and lung function during a study period of $120 \mathrm{~min}$. With the exception of venous admixture, all variables were significantly improved by means of VRMs. VT16 emerged as being superior to the P8 or Vт16+P8 VRMs, showing significant differences in all variables except for venous admixture.

Quasi-static volume-pressure curve. In contrast to the results from CRS, postmortem distensibility of the respiratory system (Fig. 3) seemed to be better in the Surf than in the P8 group. However, the results were based only on three of seven animals in the Control group, four of seven animals in the Surf group, and five of seven animals in the P8 group. Only in the Vт16 and the Vт16+P8 groups could data be obtained from all seven animals. Differences among groups would probably have been more pronounced considering that the lungs of the sickest animals in each group experienced pneumothoraces leading to exclusion from statistical analysis.

Histology score and surfactant distribution. Figure 4 displays the impact of surfactant and VRM on six histology indices that were evaluated by light microscopy of central and peripheral cuts from each of the five lobes of the lungs. Among those groups receiving surfactant, a trend toward increased leakage of proteinaceous fluid into the airways as indicated by edema and hyaline membranes was noted in the P8 and $\mathrm{V}_{\mathrm{T}} 16+\mathrm{P} 8$ groups (Fig. 4). The $\mathrm{V}_{\mathrm{T}} 16+\mathrm{P} 8$ group regularly showed desquamated and dissolved epithelia within the small bronchi and alveoli as well as small bleeding areas (Fig. 6). Moreover, peripheral emphysema could most often be found especially in the right lower lobe and the left upper lobe. Most striking was the amount of macrophages in the P8 group also regularly containing giant macrophages in the alveoli. This group was also characterized by extensive diffuse and subpleural emphysema (Fig. 7).

On macroscopic examination (Fig. 8) surfactant distribution at the subpleural level was most inhomogeneous in the Surf group. Homogeneous surfactant distribution (Fig. 9) could most often be found in the $\mathrm{V}_{T} 16$ group, occasionally even extending to the subpleural spaces. Differences in surfactant deposits among lobuli were least in this group. In contrast surfactant was generally found as little clusters in the small bronchi of the Surf group, thus preventing surfactant from entering into the alveoli (Fig. 10). Failure to recruit atelectatic areas resulted in considerably less surfactant deposition to the 


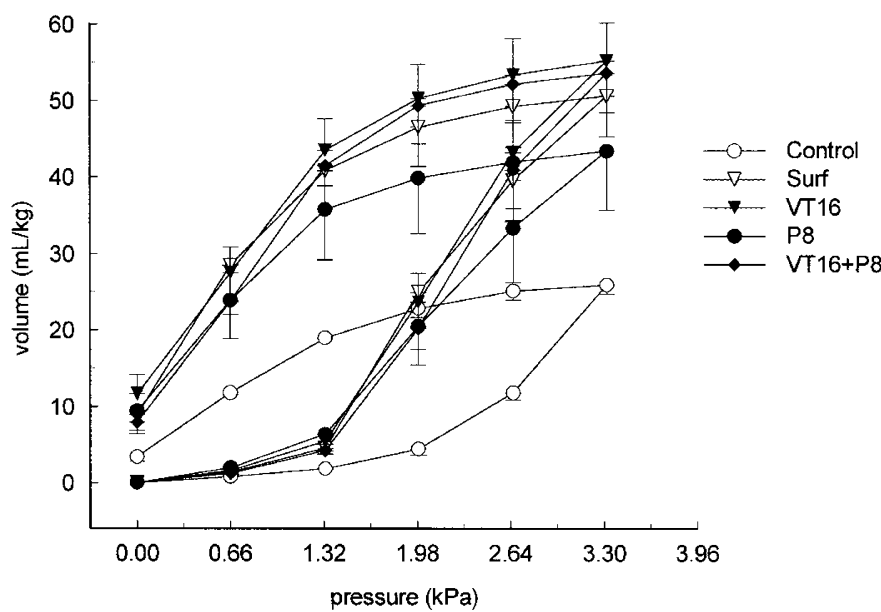

Figure 3. Quasi-static pressure-volume curves were assessed immediately postmortem with the lungs remaining in situ. Means \pm SEM. There were no statistically differences (one-way ANOVA) among the four groups receiving surfactant at $1.32 \mathrm{kPa}$ up (opening pressure), $3.3 \mathrm{kPa}$ (maximal lung volume), and $0.66 \mathrm{kPa}$ down (deflation stability).

collapsed lobuli. Lung specimens from the control group also showed erythroblasts in addition to macrophages and abundant polymorphonuclear granulocytes.

Stained surfactant deposits did not promote additional attraction of cells within the alveoli when compared with the control group (see also Fig. 4, "infiltration and invasion").

Figure 5 displays an overview of the homogeneity of stained surfactant distribution in all five lung lobes. Summarizing the scores of the five lobes in "All lobes" one can see a significant difference between the Surf group and those groups receiving a VRM while given surfactant (except Surf versus P8, $p=$ $0.05)$.

\section{DISCUSSION}

This study shows that recruitment of previously unventilated alveoli at the time of surfactant administration leads to a superior response of exogenous surfactant in the saline-lavaged lungs of newborn piglets, in terms of gas exchange, lung function, and surfactant distribution at the alveolar level. Volume recruitment was proven by improved $\mathrm{C}_{\mathrm{RS}}$ and increased FRC in all three intervention groups (Table 2). In contrast augmentation of $V_{A}$ was only seen along with increased $V_{T}$ (VT16 and $\mathrm{V}_{\mathrm{T}} 16+\mathrm{P} 8$ groups). If increased $\mathrm{V}_{\mathrm{T}}$ had only resulted in further inspiratory distention of terminal airways already being ventilated, CRS would have remained the same or decreased. The increase in $\mathrm{C}_{\mathrm{RS}}$, however, reflected the existence of a considerable compartment of alveoli not being ventilated after airway lavage. Recruitment of unventilated alveoli by the use of increased Vт promoted the exogenous surfactant effect more than higher end-expiratory volumes by means of increased PEEP. The combination of both recruitment maneuvers, however, showed no synergistic effects in terms of improvement in gas exchange and lung function. Increased alveolar ventilation at the end of the experiment (Fig. 2, observation at $120 \mathrm{~min}$ ) was linked with a more homogeneous surfactant distribution within the lungs as proven by light microscopy (Fig. 5).
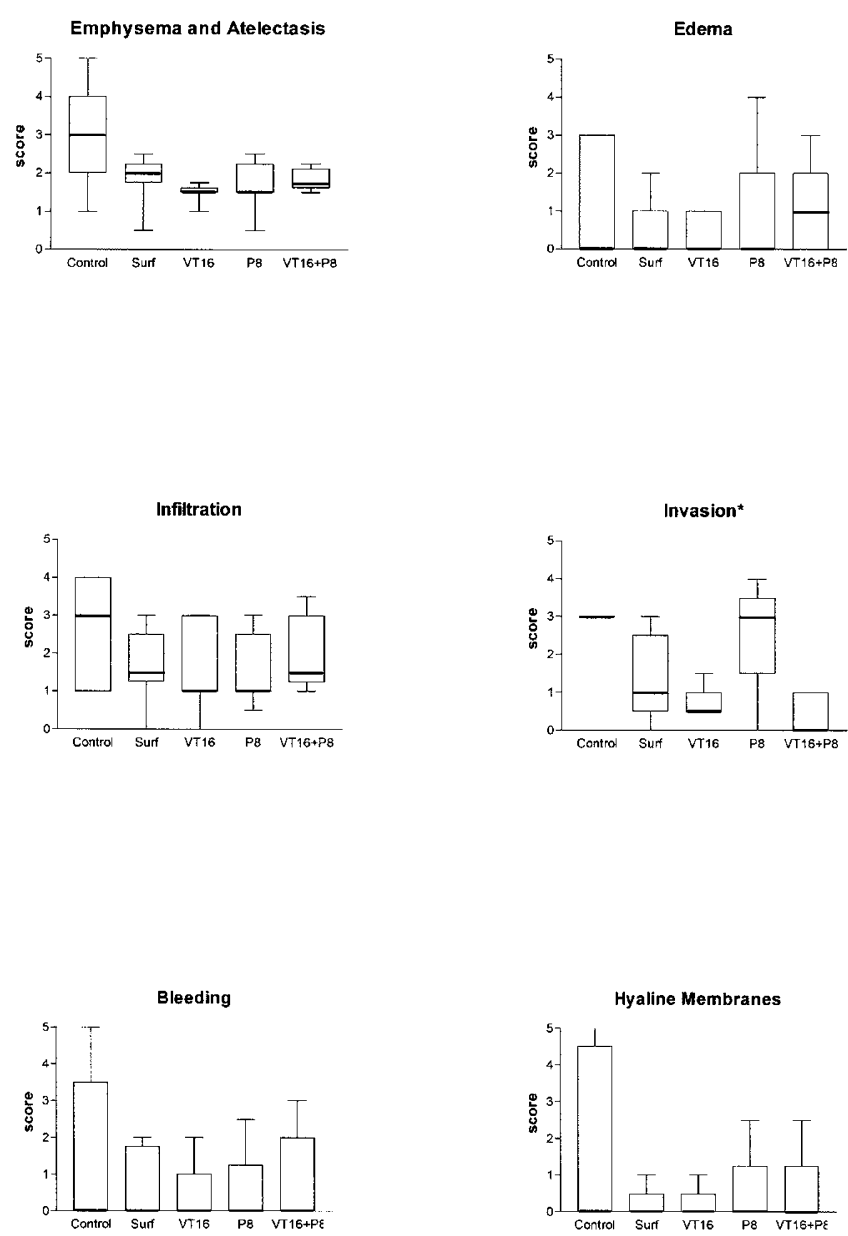

Figure 4. Box and whisker plots (boxes extending from the 25th to the 75th percentiles; median, fat line; whiskers showing the highest and lowest values) describing the following histology scores: 0 , not at all; 1 , very little; 2 , little; 3 , moderate; 4 , moderate to severe; 5 , severe (we also used steps by 0.5 points). Edema was essentially present only within the alveolar septa. Infiltration refers to the amount of polymorphonuclear leukocytes and lymphocytes in the interstitium, invasion to the presence of macrophages, giant macrophages, and erythroblasts in the lung interstitium or alveoli. To assess differences among intervention groups, the control group was not included for statistical analysis (Friedman test). ${ }^{*} p<0.05$; Dunn's multiple comparison test also showing a difference between P8 and VT16+P8 $(p<0.05)$.

Alveolar instability refers to the tendency for an alveolus to switch abruptly between the inflated state and the collapsed state. When unstable alveoli have been stabilized by surfactant repletion they deflate progressively without collapse so that they retain gas volume at end-expiratory pressures below their critical closing pressure (26). The lung model on which our hypothesis is based (11) assumes the presence of three compartments that differ in ventilation and stability: 1 ) a compartment of alveoli that are not ventilated, 2) a compartment of alveoli that are ventilated, but are unstable and collapse during expiration, and 3) a compartment of alveoli that are ventilated and do not collapse during expiration. Inhomogeneity of ventilation has been demonstrated by indicator gas washout analysis in premature lambs (27) and in premature infants with RDS (28) and is normalized by surfactant treatment. Studies with premature lambs $(5,29)$ have shown that surfactant distribution is correlated with the distribution of ventilation. 

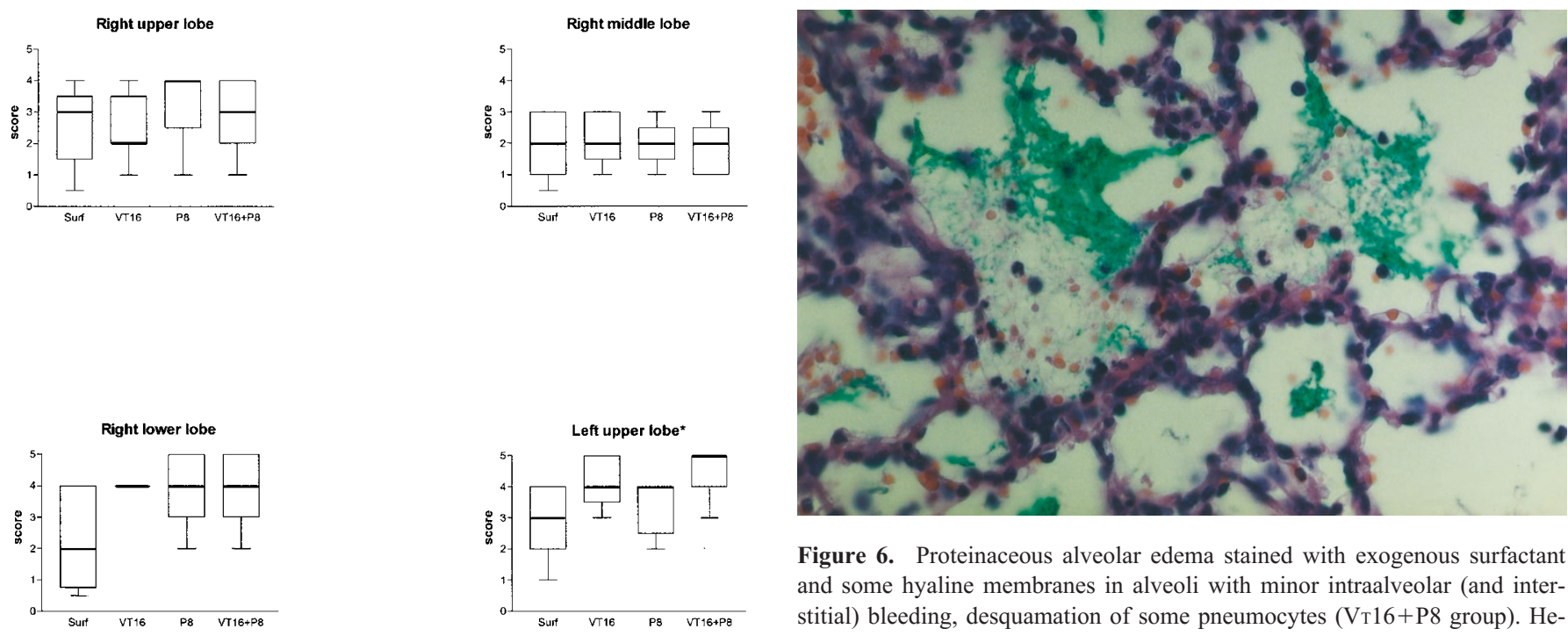

Figure 6. Proteinaceous alveolar edema stained with exogenous surfactant and some hyaline membranes in alveoli with minor intraalveolar (and interstitial) bleeding, desquamation of some pneumocytes (VT16+P8 group). Hematoxylin and eosin stain, oil $\times 1200$.
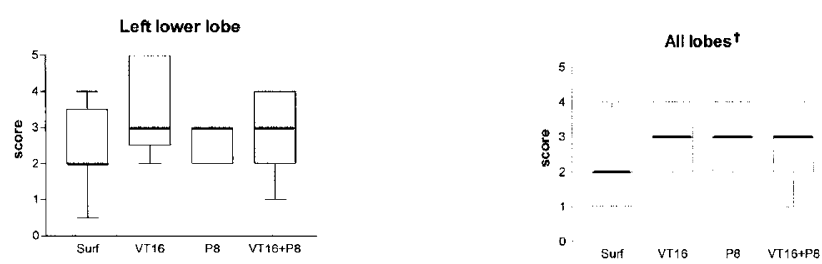

Figure 5. Box and whisker plots (boxes extending from the 25th to the 75th percentiles; median, fat line; whiskers showing the highest and lowest values) describing the following score in reference to the distribution of stained exogenous surfactant to the five lobes: $0-5$ points from 0 indicating very inhomogeneous to 5 indicating very homogeneous (we also used steps by 0.5 points; Friedman test). ${ }^{*} p<0.05$; Dunn's multiple comparison test also showing a difference between P8 and Vт16+P8 $(p<0.05)$. "All lobes" summarizes the scores of all five lobes. †Comparisons among the Surf group and those groups receiving VRM along with surfactant administration yielded the following results: Surf $v s$ Vт16, $p<0.01$; Surf $v s$ P8, $p=0.05$; Surf $v s$ Vт16 $+\mathrm{P} 8, p<0.05$ (Wilcoxon rank sum test).

From these observations, it is reasonable to expect that recruitment of previously unventilated alveoli at the time of surfactant administration would facilitate the distribution of surfactant to this compartment.

The use of VRMs after surfactant administration apparently belongs to empirically based clinical practice (e.g. Survanta package insert) in premature infants with RDS to overcome alveolar hypoventilation and has been previously proven effective (increased $\mathrm{V}_{\text {T) }}$ in an adult rabbit model (30). In contrast, the use of increased PEEP to augment end-expiratory lung volume at the time of surfactant administration does not belong to clinical routine.

All three VRMs positively influenced surfactant distribution when compared with the Surf group. The right upper and middle lobes were least influenced by VRM even though VRM in general promoted surfactant advancement from terminal bronchioli to the alveoli. Exogenous surfactant deposits to the subpleural areas was least in the small upper lobes of the

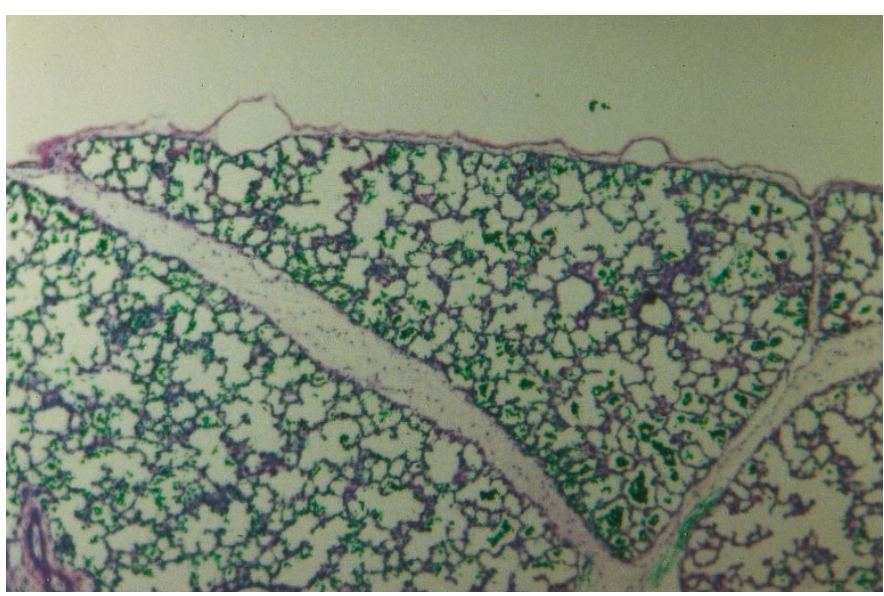

Figure 7. Subpleural emphysema and areas of alveolar overdistention in a lung demonstrating homogeneous surfactant distribution at the alveolar level (P8 group). Hematoxylin and eosin stain, $\times 300$.

piglet's lungs (Fig. 8), a finding that was also observed in a preterm lamb model of RDS (31). Differences in surfactant deposition between right and left upper lobes may be explained by the anatomic situation in the piglet with the right upper bronchus branching off directly from the trachea.

Application of large $\mathrm{V}_{\mathrm{T}}$ may be followed by VILI. VILI is likely to happen when the sum of FRC and $\mathrm{V}_{\mathrm{T}}$ exceeds maximal lung volume, being approximately $50 \mathrm{~mL} / \mathrm{kg}$ in infants with nondiseased lungs and approximately $20 \mathrm{~mL} / \mathrm{kg}$ in infants with RDS (32). Not only the degree but also the duration of overinflation is an important factor for VILI (33) and may happen after no more than a few minutes after mechanical ventilation with $\mathrm{V}_{\mathrm{T}}$ of $10 \mathrm{~mL} / \mathrm{kg}$ in premature rabbits (34) or $46 \mathrm{~mL} / \mathrm{kg}$ in adult rabbits (35). Six manual inflations of $35-40 \mathrm{~mL} / \mathrm{kg}$ (bagging) for resuscitation before the start of regular mechanical ventilation led to severe compromise in gas exchange, lung mechanics, and lung histology in a preterm lamb model of RDS (36). There are several reasons for the occurrence of VILI when using high VT in animal models of surfactant deficiency: 1) the conversion rate 


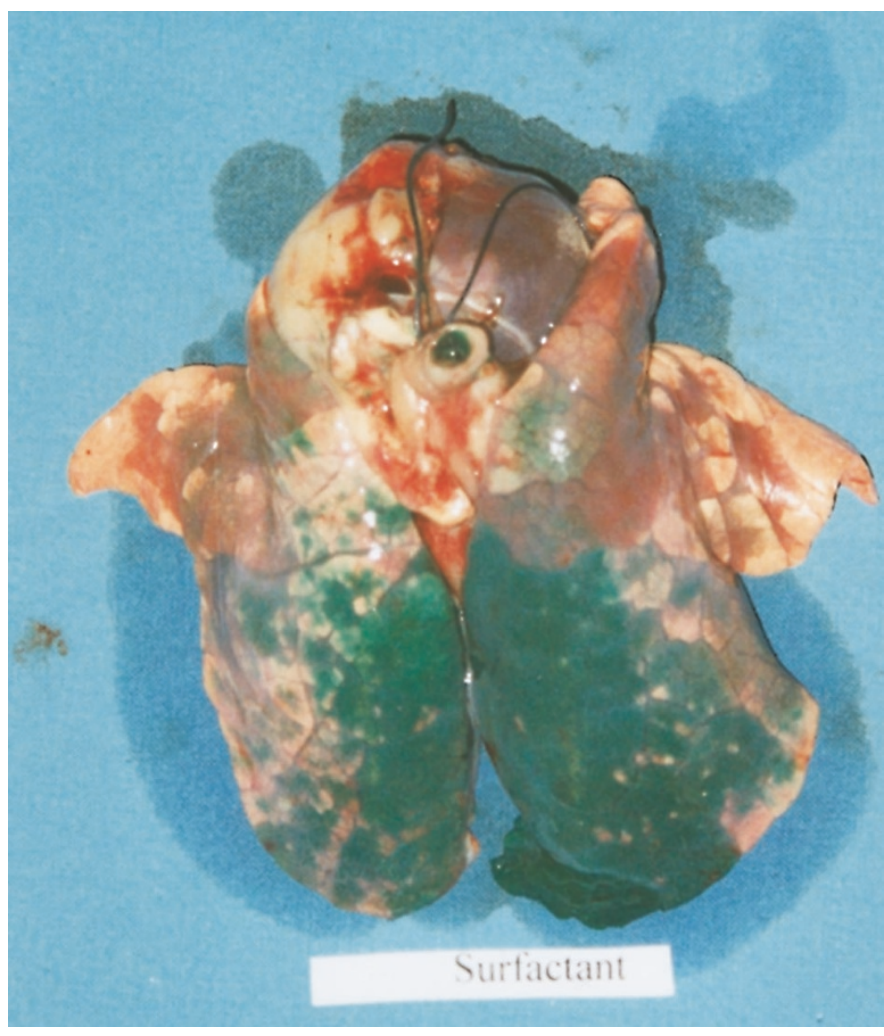

Figure 8. Dorsal aspect of excised lungs with the trachea tied off and cut off (Surf group). Grossly inhomogeneous distribution of stained surfactant at the subpleural level adjacent to areas of little or complete atelectasis. On top dorsal aspect of the heart beneath the right upper lobe.

of large aggregate to small (inactive) aggregate surfactant forms is enhanced $(37,38)$ and 2) disruption of alveolar membranes leads to increased fluid influx into the lung parenchyma thus increasing the wet-to-dry weight ratio of the lungs (39).

It has been shown in different animal models $(36,40,41)$ that VILI can be prevented when surfactant is given concomitantly with the initiation of ventilation. Moreover, VILI could not be found in a preterm sheep model of RDS using moderately high $\mathrm{V}_{\text {T }}$ of $15 \mathrm{~mL} / \mathrm{kg}$ (as in our present study for volume recruitment) in comparison with $8 \mathrm{~mL} / \mathrm{kg}$ (42). No differences in surfactant aggregate conversion or alveolar lavage protein content could be detected.

The sum of $\mathrm{V}_{\mathrm{T}}$ and FRC in our $\mathrm{V}_{\mathrm{T}} 16+\mathrm{P} 8$ group was approximately $56 \mathrm{~mL} / \mathrm{kg}$ (Fig. 2), thus probably exceeding TLC. Gas exchange and lung function indices were inferior to those of the Vт16 group, suggesting some degree of VILI in this group as demonstrated by desquamation of bronchial epithelia and higher occurrence rates for edema and hyaline membranes (Figs. 4 and 6). In contrast we assume that a short period of large Vт ventilation, although less than TLC (VT16 group), concomitantly with surfactant repletion of the lungs, will not result in VILI and that stretching of airways might rather lead to additional endogenous surfactant release (43). Not only VILI, but also peripheral emphysema at subpleural regions may have contributed to the inferior surfactant response in the $\mathrm{V}_{1} 16+\mathrm{P} 8$ group when compared with $\mathrm{V}_{\mathrm{T}} 16$ alone.

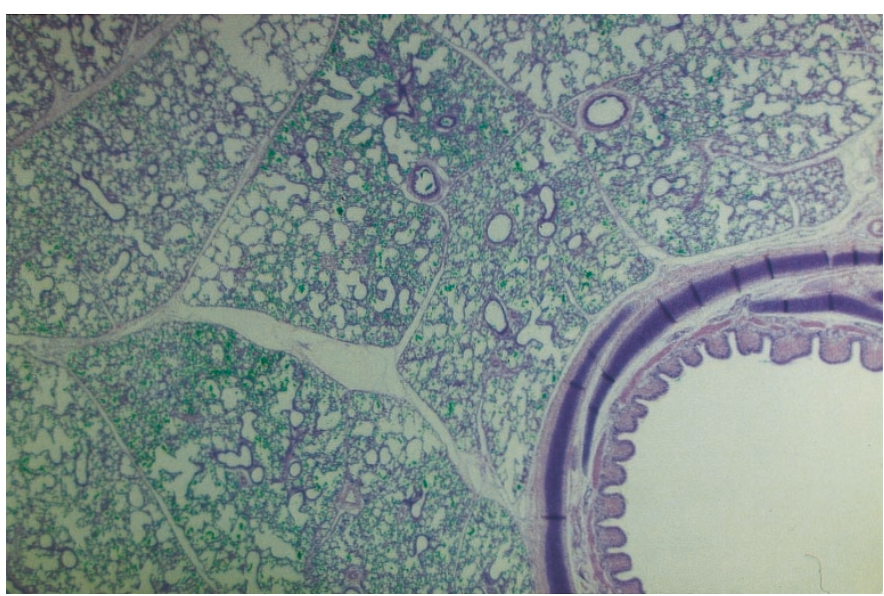

Figure 9. Homogeneous surfactant distribution showing only little variation in the amount of surfactant deposits among lobuli (VT16 group). Hematoxylin and eosin stain, $\times 150$.

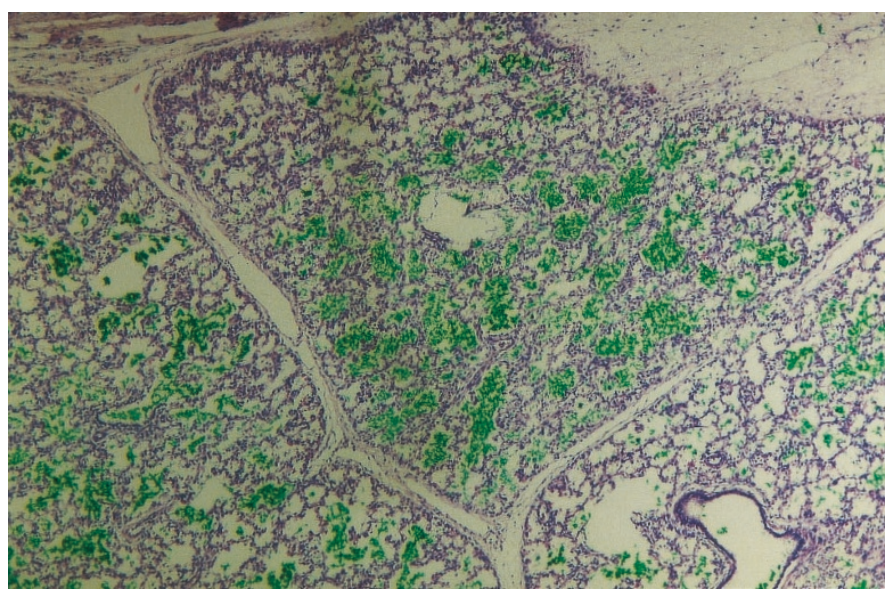

Figure 10. Clusters of stained surfactant obstructing terminal bronchi, thus preventing surfactant from entering into the alveoli or advancing to peripheral sites (Surf group). Hematoxylin and eosin stain, $\times 300$.

In mammals, during unloaded quiet breathing, $\mathrm{V}_{\text {T }}$ appears to be cross-species constant when standardized to body weight, being approximately $6-8 \mathrm{~mL} / \mathrm{kg}$ (44). We choose baseline PEEP levels of $0.4 \mathrm{kPa}$ [accounting for approximately $50 \%$ of TLC in nondiseased adult rabbit lungs (45)] and a $\mathrm{V}_{\text {T }}$ of 8 $\mathrm{mL} / \mathrm{kg}$ (until baseline) in an attempt to initially avoid lung volumes beyond TLC and to avoid circulatory compromise by lung overdistention when using $\mathrm{V}_{\mathrm{T}} \geq 20 \mathrm{~mL} / \mathrm{kg}$ and a PEEP $\geq$ $10 \mathrm{~cm} \mathrm{H}_{2} \mathrm{O}$ (46). Changes in VT after surfactant administration were allowed to assess improvement in CRs.

Evaluation of 10 histologic specimens for each experimental subject should be considered a conservative approach that tends to underestimate differences among groups. Despite limitations of the histologic method that we used to assess the absolute degree of injury, it is likely that differences in histology among groups reflect true differences in severity of injury (47). Occurrence rates of pneumothoraces while performing pressure-volume curves are another hint of differences in inhomogeneity of lung injury or, vice versa, for the homogeneity of surfactant distribution. 
The surfactant staining technique used in this study (19) allows to describe surfactant distribution at the alveolar level, also giving some information about the timely responses of, for example, surfactant incorporation into macrophages or the build-up of the exogenous surfactant layer onto hyaline membranes.

The airway lavage model in term newborn piglets may not exactly represent the physiologic and histologic situation of the structurally more immature lung of premature human infants with RDS. Airway lavage in the adult rabbit (48) leads to widespread atelectasis alternating with areas of well-expanded or even hyperexpanded alveoli, necrosis and desquamation of airway epithelium, accumulation of edema fluid, hyaline membranes, nonspecific pneumonia, intraalveolar accumulation of macrophages, and areas of interstitial and intraalveolar hemorrhage, as also seen in our piglet model of airway lavage.

Further differences between the piglet lavage model and true animal models of RDS (premature lambs or monkeys) might influence the efficacy of VRM because impaired gas exchange occurs also because of the existence of proteinaceous intraalveolar fluid next to alveolar atelectasis as shown by Jackson et al. $(49,50)$ in a premature monkey model. Moreover Neumann et al. (51) demonstrated in an adult porcine model of lung injury that atelectatic areas induced by repeated airway lavage are more easily recruitable than when caused by lung injury induced by oleic acid injection. One difference between these two models of lung injury is the degree of intraalveolar fluid accumulation.

In summary, this study shows that volume recruitment by means of moderately increased tidal volumes at the time of surfactant administration leads to augmentation of alveolar ventilation, thus improving gas exchange and lung function owing to more homogeneous surfactant distribution within the lungs. These data obtained from a neonatal piglet model of airway lavage encourage further experimental trials in a true RDS model with preterm lambs for evaluation of a preclinical situation.

Acknowledgments. The surfactant preparation used in this study (Curosurf) was (in part) generously provided by Serono Pharma, Unterschleißheim, Germany. The authors thank Artur Busch, M.A., for technical support.

\section{REFERENCES}

1. Soll RF 1995 Clinical trials of surfactant therapy in the newborn. In: Robertson B, Taeusch HW (eds) Surfactant therapy for lung disease. Marcel Dekker, New York, pp 407-442

2. Hallman M, Merritt TA, Bry K 1994 The fate of exogenous surfactant in neonates with respiratory distress syndrome. Clin Pharmacokinet 26:215-232

3. Charon A, Taeusch W, Fitzgibbon C, Smith GB, Treves ST, Phelps DS 1989 Factors associated with surfactant treatment response in infants with severe respiratory distress syndrome. Pediatrics 83:348-354

4. Segerer H, Stevens P, Schadow B, Maier R, Kattner E, Schwarz H, Curstedt T, Robertson B, Obladen M 1991 Surfactant substitution in ventilated very low birth weight infants: factors related to response types. Pediatr Res 30:591-596

5. Jobe AH, Ikegami M, Jacobs H, Jones S 1984 Surfactant and pulmonary blood flow distributions following the treatment of premature lambs with natural surfactant. $\mathrm{J}$ Clin Invest 73:848-856

6. Van der Bleek J, Plotz FB, Overbeek FM, Heikamp A, Beekhuis H, Wildevuur CRH, Okken A, Bambang Oetomo S 1993 Distribution of exogenous surfactant in rabbits with severe respiratory failure: the effect of volume. Pediatr Res 34:154-158

7. Segerer H, van Gelder W, Angenent FWM, van Woerkens LJPM, Curstedt T, Obladen M, Lachmann B 1993 Pulmonary distribution and efficacy of exogenous surfactant in lung-lavaged rabbits are influenced by the instillation technique. Pediatr Res 34:490-494

8. Edberg KE, Ekström-Jodal B, Hallman M, Hjalmarson O, Sandberg K, Silberberg A 1990 Immediate effects on lung function of instilled human surfactant in mechanically ventilated newborn infants with IRDS. Acta Paediatr Scand 79:750-755

9. Goldsmith LS, Greenspan JS, Rubenstein SD, Wolfson MR, Shaffer TH 1991 Immediate improvement in lung volume after exogenous surfactant: alveolar recruitment versus increased distention. J Pediatr 119:424-428

10. Cotton RB, Olsson T, Law AB, Parker RA, Lindstrom DP, Silberberg AR, Sundell HW, Sandberg K 1993 The physiological effects of surfactant treatment on gas exchange in newborn premature infants with hyaline membrane disease. Pediatr Res 34:495-501

11. Cotton RB 1994 A model of the effect of surfactant treatment on gas exchange in hyaline membrane disease. Semin Perinatol 18:19-22

12. Davis JM, Veness-Meehan K, Notter RH, Bhutani VK, Kendig JW 1988 Changes in pulmonary mechanics after the administration of surfactant to infants with respiratory distress syndrome. N Engl J Med 319:476-479

13. Bhutani VK, Abbasi S, Long WA, Gerdes JS 1992 Pulmonary mechanics and energetics in preterm infants who had respiratory distress syndrome treated with synthetic surfactant. J Pediatr 120(suppl):S18-S24

14. Lachmann B, Robertson B, Vogel J 1980 In vivo lung lavage as an experimental model of the respiratory distress syndrome. Acta Anaesth Scand 24:231-236

15. Krause MF, Hoehn T 1999 Decrease in lung volume depends on end-expiratory pressure in a rabbit model of airway lavage. Respiration 66:259-264

16. Oyarzún MJ, Clements JA 1978 Control of lung surfactant by ventilation, adrenergic mediators, and prostaglandins in the rabbit. Am Rev Respir Dis 117:879-891

17. Massaro D, Clerch L, Massaro GD 1982 Surfactant secretion: evidence that cholinergic stimulation of secretion is indirect. Am J Physiol 243:C39-C45

18. Dijk PH, Heikamp A, Bambang Oetomo S 1997 Surfactant nebulization: lung function, surfactant distribution and pulmonary blood flow distribution in lung lavaged rabbits. Intensive Care Med 23:1070-1076

19. Krause MF, Orlowska-Volk M, Hendrik ER, Gommers D, Lachmann B 2000 A new simple method of staining exogenous surfactant in experimental research. Eur Respir J 15:949-954

20. Krause MF, Schulte-Mönting J, Hoehn T 1998 Rate of surfactant administration influences lung function and gas exchange in a surfactant-deficient rabbit model. Pediatr Pulmonol 25:196-204

21. Sjöqvist BA, Sandberg K, Hjalmarson O, Olsson T 1984 Calculation of lung volume in newborn infants by means of a computer-assisted nitrogen washout method. Pediatr Res 18:1160-1164

22. Sjöqvist BA, Sandberg K, Hjalmarson O, Olsson T 1986 Method for analysing multiple-breath nitrogen washout. Med Biol Eng Comput 24:83-90

23. Edberg KE, Sandberg K, Silberberg A, Sjöqvist BA, Ekström-Jodal B, Hjalmarson O 1991 A plethysmographic method for assessment of lung function in mechanically ventilated very low birth weight infants. Pediatr Res 30:501-504

24. Venegas JG, Harris RS, Simon BA 1998 A comprehensive equation for the pulmonary pressure volume curve. J Appl Physiol 84:389-395

25. Jobe AH 1993 Pulmonary surfactant therapy. N Engl J Med 328:861-868

26. Clements JA, Hustead RF, Johnson RP, Gribetz I 1961 Pulmonary surface tension and alveolar stability. J Appl Physiol 16:444-450

27. Vilstrup C, Gommers D, Bos JAH, Lachmann B, Werner O, Larsson A 1992 Natural surfactant instilled in premature lambs increases volume and improves ventilation homogeneity within five minutes. Pediatr Res 32:595-599

28. Sandberg KL, Lindstrom DP, Sjöqvist BA, Parker RA, Cotton RB 1997 Surfactant replacement therapy improves ventilation inhomogeneity in infants with respiratory distress syndrome. Pediatr Pulmonol 24:337-343

29. Ueda T, Ikegami M, Rider ED, Jobe AH 1994 Distribution of surfactant and ventilation in surfactant-treated preterm lambs. J Appl Physiol 76:45-55

30. Krause M, Olsson T, Law AB, Parker RA, Lindstrom DP, Sundell HW, Cotton RB 1997 Effect of volume recruitment on response to surfactant treatment in rabbits with lung injury. Am J Respir Crit Care Med 156:862-866

31. Pinkerton KE, Lewis JF, Rider ED, Plake J, Chen W, Madl AK, Luu RH, Ikegami M, Jobe AH 1994 Lung parenchyma and type II cell morphometrics: effect of surfactant treatment on preterm ventilated lamb lungs. J Appl Physiol 77:1953-1960

32. Vilstrup CT, Björklund LJ, Werner O, Larsson A 1996 Lung volumes and pressurevolume relations of the respiratory system in small ventilated neonates with severe respiratory distress syndrome. Pediatr Res 39:127-133

33. Dreyfuss D, Saumon G 1994 Should the lung be rested or recruited? The Charybdis and Scylla of ventilator management Am J Respir Crit Care Med 149:1066-1068

34. Nilsson R, Grossmann G, Robertson B 1980 Bronchiolar epithelial lesions induced in the premature rabbit neonate by short periods of artificial ventilation. Acta Pathol Microbiol Scand 88:359-367

35. Dreyfuss D, Soler P, Saumon G 1992 Spontaneous resolution of pulmonary edema caused by short periods of cyclic overinflation. J Appl Physiol 72:2081-2089

36. Björklund LJ, Ingimarsson J, Curstedt T, John J, Robertson B, Werner O, Vilstrup CT 1997 Manual ventilation with few large breaths at birth compromises the therapeutic effect of subsequent surfactant replacement in immature lambs. Pediatr Res 42:348355

37. Veldhuizen RA, Marcon J, Yao L-J, McCaig L, Ito Y, Lewis JF 1996 Alveolar surfactant aggregate conversion in ventilated normal and injured rabbits. Am J Physiol 270:L152-L158

38. Ito Y, Manwell SEE, Kerr CL, Veldhuizen RAW, Yao LJ, Bjarneson D, McCaig LA, Bartlett AJ, Lewis JF 1998 Effects of ventilation strategies on the efficacy of exogenous surfactant therapy in a rabbit model of acute lung injury. Am J Respir Crit Care Med 157:149-155 
39. Carlton DP, Cummings JJ, Scheerer RG, Poulain FR, Bland RD 1990 Lung overexpansion increases pulmonary microvascular protein permeability in young lambs. J Appl Physiol 69:577-583

40. Nilsson R, Berggren P, Curstedt T, Grossmann G, Renheim G, Robertson B 1985 Surfactant treatment and ventilation by high-frequency oscillation in premature newborn rabbits: effect on survival, lung aeration, and bronchiolar epithelial lesions. Pediatr Res 19:143-147

41. Wada K, Jobe AH, Ikegami M 1997 Tidal volume effects on surfactant treatment responses with the initiation of ventilation in preterm lambs. J Appl Physiol 83:10541061

42. Ikegami M, Wada K, Emerson GA, Rebello CM, Hernandez RE, Jobe AH 1998 Effects of ventilation style on surfactant metabolism and treatment response in preterm lambs. Am J Respir Crit Care Med 157:638-644

43. Nicholas TE, Barr HA 1983 The release of surfactant in rat lung by brief periods of hyperventilation. Respir Physiol 52:69-83

44. Stick S 1996 Measurements during tidal breathing. In: Stocks J, Sly PD, Tepper RS, Morgan WJ (eds) Infant respiratory function testing. Wiley-Liss, New York, pp $117-138$

45. Shen X, Gunst SJ, Tepper RS 1997 Effect of tidal volume and frequency on airway responsiveness in mechanically ventilated rabbits. J Appl Physiol 83:1202-1208
46. Cheifetz IM, Craig DM, Quick G, McGovern JJ, Cannon ML, Ungerleider RM, Smith PK, Meliones JN 1998 Increasing tidal volumes and pulmonary overdistention adversely affects pulmonary vascular mechanics and cardiac output in a pediatric swine model. Crit Care Med 26:710-716

47. Broccard AF, Shapiro RS, Schmitz LL, Ravenscraft SA, Marini JJ 1997 Influence of prone position on the extent and distribution of lung injury in a high tidal volume oleic acid model of acute respiratory distress syndrome. Crit Care Med 25:16-27

48. Lachmann B, Jonson B, Lindroth M, Robertson B 1982 Modes of artificial ventilation in severe respiratory distress syndrome: lung function and morphology in rabbits after wash-out of alveolar surfactant. Crit Care Med 10:724-732

49. Jackson JC, Standaert TA, Truog WE, Murphy JH, Palmer S, Chi EY, Woodrum DE, Watchko JF, Hodson WA 1985 Changes in lung volume and deflation stability in hyaline membrane disease. J Appl Physiol 59:1783-1789

50. Jackson JC, Mackenzie AP, Chi EY, Standaert TA, Truog WE, Hodson WA 1990 Mechanisms for reduced total lung capacity at birth and during hyaline membrane disease in premature newborn monkeys. Am Rev Respir Dis 142:413-419

51. Neumann P, Berglund JE, Fernández Mondéjar E, Magnusson A, Hedenstierna G 1998 Dynamics of lung collapse and recruitment during prolonged breathing in porcine lung injury. J Appl Physiol 85:1533-1543 